\title{
Event-Specific Real-Time Detection and Quantification of Genetically Modified Roundup Ready Soybean
}

\author{
Chia-Chia Huang And Tzu-Ming Pan*
}

Institute of Microbiology and Biochemistry, National Taiwan University, Taipei, Taiwan 106

\begin{abstract}
The event-specific real-time detection and quantification of Roundup Ready soybean (RRS) using an ABI PRISM 7700 sequence detection system with light upon extension (LUX) primer was developed in this study. The event-specific primers were designed, targeting the junction of the RRS 5 ' integration site and the endogenous gene lectin1. Then, a standard reference plasmid was constructed that carried both of the targeted sequences for quantitative analysis. The detection limit of the LUX realtime PCR system was $0.05 \mathrm{ng}$ of $100 \%$ RRS genomic DNA, which was equal to 20.5 copies. The range of quantification was from 0.1 to $100 \%$. The sensitivity and range of quantification successfully met the requirement of the labeling rules in the European Union and Taiwan.
\end{abstract}

KEYWORDS: Real-time PCR; light upon extension (LUX); genetically modified organisms (GMOs); RRS

\section{INTRODUCTION}

Due to the great advances in agricultural biotechnology, scientists are able to use artificial genetic manipulations to successfully transfer herbicide-tolerant, insect-resistant genes into traditional crops. Since 1996, many transgenic plants have been grown widely and sold in the global market (1). In addition, people are paying more attention to environmental impacts, ethical issues, global trade, and food safety (2). The most important of all is food safety; every country needs to set up regulations to restrict the technology or sale of food products derived from biotechnology while taking both biotechnology development and the rights of the consumers into account. The development and application of reliable detection and quantitative analytical methods are essential for the implementation of labeling requirements. Several laboratories have developed methods based either on DNA detection using the Polymerase Chain Reaction (PCR) or on protein detection using enzymelinked immunosorbent assays (ELISA) methods. Mass spectrometry, chromatography, near-infrared spectrometry, microfabricated devices, DNA chip technology, and nanoscale genetically modified organism (GMO) analysis are also used (3).

Real-time PCR, which allows monitoring of the accumulation of PCR product at any time point during the amplification reaction, enables the investigator to identify the cycles of nearlogarithmic PCR product generation. The ABI Prism 7700 system (Applied Biosystems Division, Perkin-Elmer, Foster City, CA) uses a standard $0.2 \mathrm{~mL}$ tube design for the amplification reaction. For high-throughput quantative PCR, the ABI Prism 7700 is suitable due to its 96-well format and its greater ability for automation (4).

* Address correspondence to this author at the Institute of Microbiology and Biochemistry, National Taiwan University, 1 Sec. 4, Roosevelt Rd., Taipei, Taiwan 106 (fax +886-2-23627044; telephone +886-2-23630231, ext. 3813; e-mail tmpan@ntu.edu.tw).
A fluorescence-based, real-time PCR technique that utilizes a fluorogenic primer labeled only with a single fluorophore was recently developed as a cost-effective alternative to other fluorescence-based PCR techniques (5). These other techniques, such as TaqMan probe, Molecular Beacon, Scorpion primer, Hybridization probe, Ampliflour, DNA-binding dyes (SYBR green), and others, may be reviewed elsewhere (6). The fluorogenic primer method, however, has some advantages over other methods that include the ease of design and synthesis of the fluorogenic primers. Other advantages and disadvantages are listed in previous works $(7,8)$.

The fluorogenic primer is designed to be self-quenched until it is incorporated into a double-stranded PCR product, whereupon its fluorescence increases, that is, is dequenched. The fluorogenic primer is called a LUX primer, meaning light upon extension. The counterpart PCR primer used in conjunction with the fluorogenic primer is a standard, unlabeled oligonucleotide. LUX primer design is based on studies that demonstrate the effects of the primary and secondary structures of oligonucleotides on the emission properties of a conjugated fluorophore (5).

The design factors are largely based on the necessity of having guanosine bases in the primary sequence nearby the conjugated fluorophore. The fluorophore may be various commonly used dyes such as FAM (5'- or 6'-carboxyfluorescein) and JOE (6carboxy-4', $5^{\prime}$-dichloro-2', $7^{\prime}$-dimethoxyfluorescein). Furthermore, the LUX primers have a non-sequence-specific $5^{\prime}$-tail that is complementary to the $3^{\prime}$-end of the primer. The $5^{\prime}$-tail enables the primer to assume a hairpin conformation at temperatures below the melting point of the hairpin, and it also affects the fluorescence of the LUX primer (7). The above characteristics and other standard characteristics of the primers, such as length and $T_{\mathrm{m}}$, are included in the primer design by proprietary software, called LUX Designer (Invitrogen, http://www.invitrogen.com/lux). These design rules enable the software to output 
Table 1. Primer Sequences Used To Detect Transgenic Soybean

\begin{tabular}{|c|c|c|c|c|c|c|}
\hline PCR system & & primer name & sequence $\left(5^{\prime}-3^{\prime}\right)$ & target & $\begin{array}{l}\text { amplicon } \\
\text { (bp) }\end{array}$ & $\begin{array}{c}\text { ref/ } \\
\text { Genbank }\end{array}$ \\
\hline $\begin{array}{l}\text { construction of pRRS- } \\
\text { LUX }\end{array}$ & & $\begin{array}{l}\text { TLec1618RL } \\
\text { TRRS190FL }\end{array}$ & $\begin{array}{l}\text { TCATTGCGATTTTGTAGGAACCAAT } \\
\text { CTCTCCGATTGGTTCCTACAAAATCGC }\end{array}$ & junction of amplicons I and II & & this study \\
\hline \multirow[t]{2}{*}{ real-time PCR } & $A$ & $\begin{array}{l}\text { Lec1439FU } \\
\text { Lec1618RL }\end{array}$ & $\begin{array}{l}\text { CAAGTCGTCGCTGTTGAGTTT } \\
\text { GAACCAATCGGAGAGGATATTGCTGGTTC }\end{array}$ & $l e 1^{a}$ & 228 & K00821 \\
\hline & B & $\begin{array}{l}\text { RRS190FL } \\
\text { RRS238RU }\end{array}$ & $\begin{array}{l}\text { CTACAAAATCGCAATGATGGCATTTGTAG } \\
\text { CAGGTTAAAATAAACATAGGGAA }\end{array}$ & soybean genome/P35S ${ }^{b}$ & 77 & AJ308514 \\
\hline
\end{tabular}

a lectin 1, soybean-specific single copy gene. ${ }^{b} \mathrm{P}-35 \mathrm{~S}$, cauliflower mosaic virus $35 \mathrm{~S}$ promoter.

numerous prime pairs that are located throughout the target (input) sequence.

Several laboratories have developed methods detecting the GM soybean, Roundup Ready soybean (RRS), which covers most of the output in the world. The $5^{\prime}$ and $3^{\prime}$ junction regions at the insertion sites of the transgene sequence in the genome of RRS have recently been characterized (9). Our study utilized the sequence data containing the $5^{\prime}$ junction (GenBank Accession AJ308514) to design and develop an event-specific assay for the quantitative detection of RRS. This represents the first report of the useful model of the LUX system for the eventspecific GMO detection and quantification of the $5^{\prime}$ junction of a widely grown GM crop, RRS.

\section{MATERIALS AND METHODS}

Materials. Certified reference materials IRMM-411 (Bt-176) and IRMM-411 (RRS), containing 0, 0.1, 0.5, 1, 2, and 5\% GM material, were both purchased from Sigma (St. Louis, MO). Traditional soybean (MT21) and RRS (Monsanto, St. Louis, MO) were provided by the American Soybean Association. Seeds of three lines of GM maize, that is, the insect-resistant MON810 and the glyphosate-tolerant GA21 and NK603, were developed and provided by Monsanto Co. Tainung No. 2 maize (non-GMO) was provided by Dr. Hwang, Wen-Dar (Department of Agoronomy, National Taiwan University). Japonica rice, longgrain glutinous rice, and round-grain glutinous rice were provided by Dr. Lai, Hsi-Mei (Department of Agricultural Chemistry, National Taiwan University). Other cereals were purchased from a seed store in Taipei county.

Methods. DNA Extraction. Cereal seeds were frozen by liquid nitrogen and then ground into smooth powder by a Barista blade-grinder (Starbucks Coffee, Seattle, WA). Ground powders were taken for DNA extraction. DNA was extracted according to the cetyltrimethylammonium bromide $(\mathrm{CTAB})$ method $(10)$. The ground seed powder $(100$ $\mathrm{mg}$ ) was transferred to a sterile Eppendorf containing $500 \mu \mathrm{L}$ of CTAB buffer (20 g of CTAB/L, $1.4 \mathrm{M} \mathrm{NaCl}, 0.1 \mathrm{M}$ Tris-HCl, $20 \mathrm{mM}$ EDTA) and $10 \mu \mathrm{L}$ of RNase A solution $(0.5 \mathrm{mg} / \mathrm{mL})$ (Sigma). After incubation for $30 \mathrm{~min}$ at $65{ }^{\circ} \mathrm{C}$, the mixture was then centrifuged for $10 \mathrm{~min}$ at $12000 \mathrm{~g}$. The upper layer was extracted with an equal volume of CI solution (chloroform/isoamyl alcohol $=24: 1$ ). After mixing for $30 \mathrm{~s}$, the mixture was centrifuged for $10 \mathrm{~min}$ at $11500 \mathrm{~g}$. The supernatant was transferred to a new tube, and 2 volumes of CTAB precipitation solution $(5 \mathrm{~g}$ of $\mathrm{CTAB} / \mathrm{L}, 0.04 \mathrm{M} \mathrm{NaCl})$ was added. The mixture was incubated for $60 \mathrm{~min}$ at room temperature and centrifuged for $5 \mathrm{~min}$ at $12000 \mathrm{~g}$. The supernatant was removed, and the precipitate was dissolved in $350 \mu \mathrm{L}$ of $1.2 \mathrm{M} \mathrm{NaCl}$. This solution was CI extracted. The upper layer (aqueous phase) was transferred to a new tube, and 0.7 volumes of 2-propanol was added and then centrifuged. The resulting DNA pellet was washed with ice-cold $70 \%$ ethanol and centrifuged. The ethanol layer was discarded, and the residual ethanol was removed by evaporation. The DNA pellet was resolved in double-distilled water. The plasmid DNA was extracted and purified with the Mini-M plasmid DNA extraction system (Viogene, Taipei, Taiwan). DNA concentrations were determined by $\mathrm{OD}_{260}$ (TCP-20H, Vilber Lourment Co., Marne la Vallee, France).

DNA concentration $(\mu \mathrm{g} / \mathrm{mL})=\left(\mathrm{OD}_{260}\right) \times($ dilution factor $) \times$ $(50 \mu \mathrm{g}$ of $\mathrm{DNA} / \mathrm{mL}) /\left(1 \mathrm{OD}_{260}\right.$ unit $)$

Primers and Probes. Sequences of primers listed in Table 1 were designed using the LUX designer (Invitrogen Life Technology, Carlsbad, CA) and the Primer Premier 5 (PREMIER Biosoft Int., Palo Alto, CA).

The real-time PCR systems A and B were used to quantify soybean and RRS magnitude, respectively. Primers TLec1618RL and TRRS190FL were used in connecting the amplicons of real-time PCR systems A and B. Therefore, primer TLec1618RL was designed to carry the partial primer Lec1618 sequence and the partial complementary sequence of primer RRS190FL; primer TRRS190FL was designed to carry the partial primer RRS190FL sequence and the partial complementary sequence of primer RRS190FL.

Reference Molecules. To connect the amplicons of PCR as reference molecules for RRS, we followed the method reported by Kuribara et al. (11) (Figure 1). The reference molecule was used for the calibration of RRS quantificaiton.

The amplicon III was ligated into pGEM-T-Easy Vector (Promega, Madison, WI) by using TA cloning. The sequence of plasmid pLUXRRS was validated by sequencing (Bioscience Co., Ltd., Taipei, Taiwan).

Real-Time PCR. Final concentrations of real-time PCR components were as follows: $25 \mu \mathrm{L}$ of $1 \times$ Platinum Quantitative PCR SuperMixUDG (Invitrogen Life Technologies Inc.), $1 \times$ reference dye ROX (6carboxyrhodamine), 1.5 unit of platinum Taq DNA polymerase, $20 \mathrm{mM}$ Tris- $\mathrm{HCl}$ (pH 8.0), $50 \mathrm{mM} \mathrm{KCl,} 3 \mathrm{mM} \mathrm{NaCl}, 200 \mu \mathrm{M}$ dNTP (dGTP, dCTP, and dATP), $400 \mu \mathrm{M}$ dUTP, 1 unit of uracil-DNA glycosylase (UDG), and $200 \mathrm{nM}$ passive reference dye ROX, $200 \mathrm{nM}$ primers Lec1439FU/Lec1618RL and RRS190FL/RRS238RU, and $200 \mathrm{ng}$ of DNA of samples. The PCR conditions on the ABI PRISM 7700 sequence detection system (Applied Biosystems) were as follows: first step, 2 min at $50{ }^{\circ} \mathrm{C}$ and $2 \mathrm{~min}$ at $95{ }^{\circ} \mathrm{C}$; second step, $15 \mathrm{~s}$ at $95{ }^{\circ} \mathrm{C}$ and $1 \mathrm{~min}$ at $60{ }^{\circ} \mathrm{C}, 45$ cycles.

After PCR amplification, $T_{\mathrm{m}}$ curve analysis was performed using the Dissociation Curve Analysis software v 1.0 (Applied Biosystems). The PCR products were heated to $95^{\circ} \mathrm{C}$ during $15 \mathrm{~s}$, cooled at $60^{\circ} \mathrm{C}$ for $20 \mathrm{~s}$, and then slowly heated to $95{ }^{\circ} \mathrm{C}$ at a rate of $0.2{ }^{\circ} \mathrm{C} / \mathrm{s}$. The obtained fluorescence signals were continuously monitored during the slow warming-up gradient and showed a decreasing curve with a sharp fluorescence drop near the denaturation temperature. Plotting the negative derivate of the fluorescence over temperature versus the temperature $(-\mathrm{d} F / \mathrm{d} T$ versus $T)$ generated peaks from which the $T_{\mathrm{m}}$ of the products were calculated. Unless specifically stated, all reactions were performed in triplicate.

\section{RESULTS AND DISCUSSION}

Design of the PCR System. The sequences of $5^{\prime}$ and $3^{\prime}$ integration site (GeneBank Accession No. AJ308514 and AJ308515) were input to the LUX designer, and primers were designed by the LUX designer. Only two LUX primers at the 5' integration site, RRS35FL and RRS190FL, which obtained 


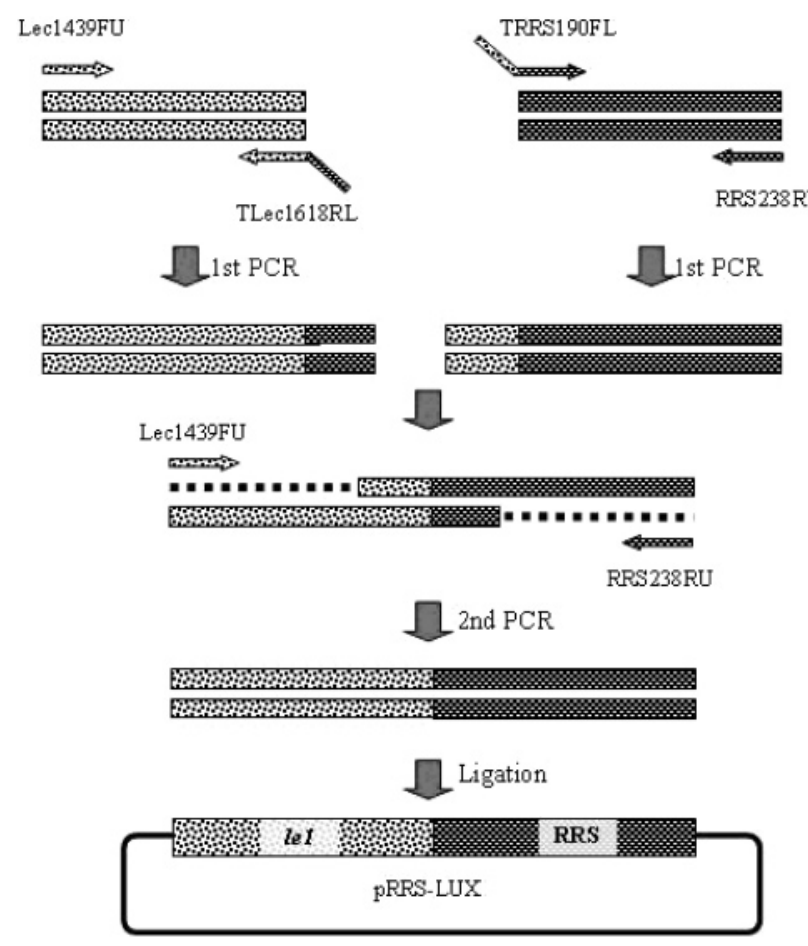

W Amplicon II amplified by RRS190FL/RRS238RU

Figure 1. Schematic diagrams of hybrid amplicon and construction of plasmid DNA as reference molecule.

the best score of 0.00 , were chosen. However, there was no applicable LUX primer at the $3^{\prime}$ integration site. Corresponding unlabeled primers were designed by Primer Premier 5. After a pretest of real-time PCR, primers RRS190FL and RRS238RU
Table 2. Cereals and Beans Used in This Study

\begin{tabular}{ll}
\multicolumn{1}{c}{ common name } & \multicolumn{1}{c}{ scientific name } \\
\hline japonica rice & Oryza sativa L. \\
indica rice & Oryza sativa L. \\
long-grain glutinous rice & Oryza sativa L. \\
round-grain glutinous rice & Oryza sativa L. \\
oat & Avena sativa \\
barley & Hordeum vulgare \\
wheat & Triticum aestivum \\
traditional soybean MT21 (non-GMO) & Glycine max (L.) Merr. \\
Roundup Ready soybean & Glycine max (L.) Merr. \\
black soybean & Glycine max (L.) Merr. \\
adzuki bean & Phaseolus angularis (Willd.) \\
& W. Wight \\
mung bean & Phaseolus aureus Roxb. \\
multiflora bean, kidney bean & Phaseolus coccineus L. \\
cowpea & Vigna sinensis (L.) Savi ex \\
& Hassk \\
peanut & Arachis hypogaea L. \\
Tainung No. 2 maize (non-GMO) & Zea mays \\
Roundup Ready corn, GA21 & Zea mays \\
Roundup Ready corn, NK603 & Zea mays \\
Yield Gard, corn borer, MON810 & Zea mays \\
KnockOut, NatureGard, Maximizer, & Zea mays \\
Event 176 & \\
\hline
\end{tabular}

Table 3. Sensitivity of the LUX Real-Time PCR

\begin{tabular}{lccccccc}
\hline & \multicolumn{7}{c}{$100 \%$ RRS genomic DNA (ng) } \\
\cline { 2 - 8 } LUX signal ratio & 50 & 12.5 & 2.5 & 0.5 & 0.05 & 0.025 & 0.0025 \\
\hline of RRS transgene & $9 / 9$ & $9 / 9$ & $9 / 9$ & $9 / 9$ & $9 / 9$ & $6 / 9$ & $0 / 9$ \\
of le1 & $9 / 9$ & $9 / 9$ & $9 / 9$ & $9 / 9$ & $9 / 9$ & $6 / 9$ & $1 / 9$
\end{tabular}

a Signal ratio indicates positive signal for each of the target gene/total reaction (nine replicates).

were chosen. In addition, primers Lec1439FU and Lec1618RL were chosen by the same process. Primers Lec1439FU/ Lec1618RL were used to amplify the endogenous gene, lectin1 (le1), of soybean.

The only unique signature of a transformation event (within the limitations of present-day technology) is the junction at the

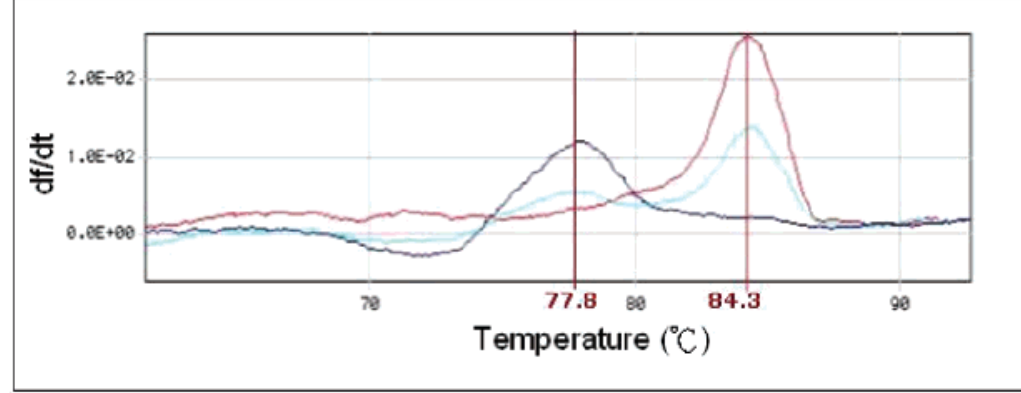

(A)

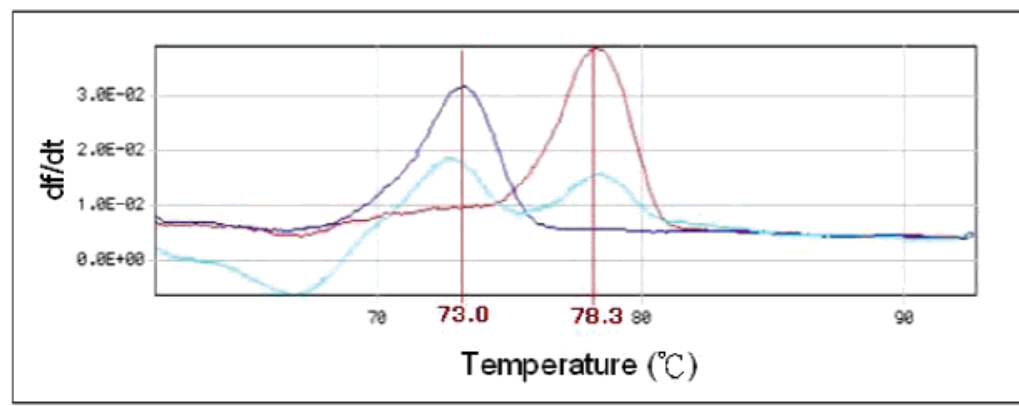

(B)

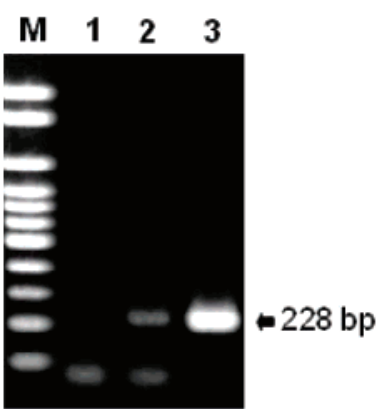

(C)

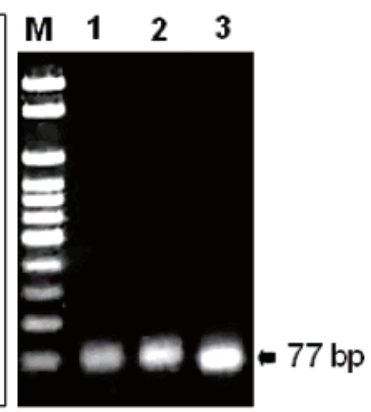

(D)

Figure 2. Melting curve plots and electrophoretic analysis of the real-time PCR products. Primers: (A, C) Lec1618RL/Lec1439FU; (B, D) RRS190FL/ RRS238RU; (dark blue graph and lane 1) NTC; (light blue graph and lane 2) $5 \mathrm{ng}$ of 100\% RRS genomic DNA; (red graph and lane 3) $100 \mathrm{ng}$ of $100 \%$ RRS genomic DNA. 


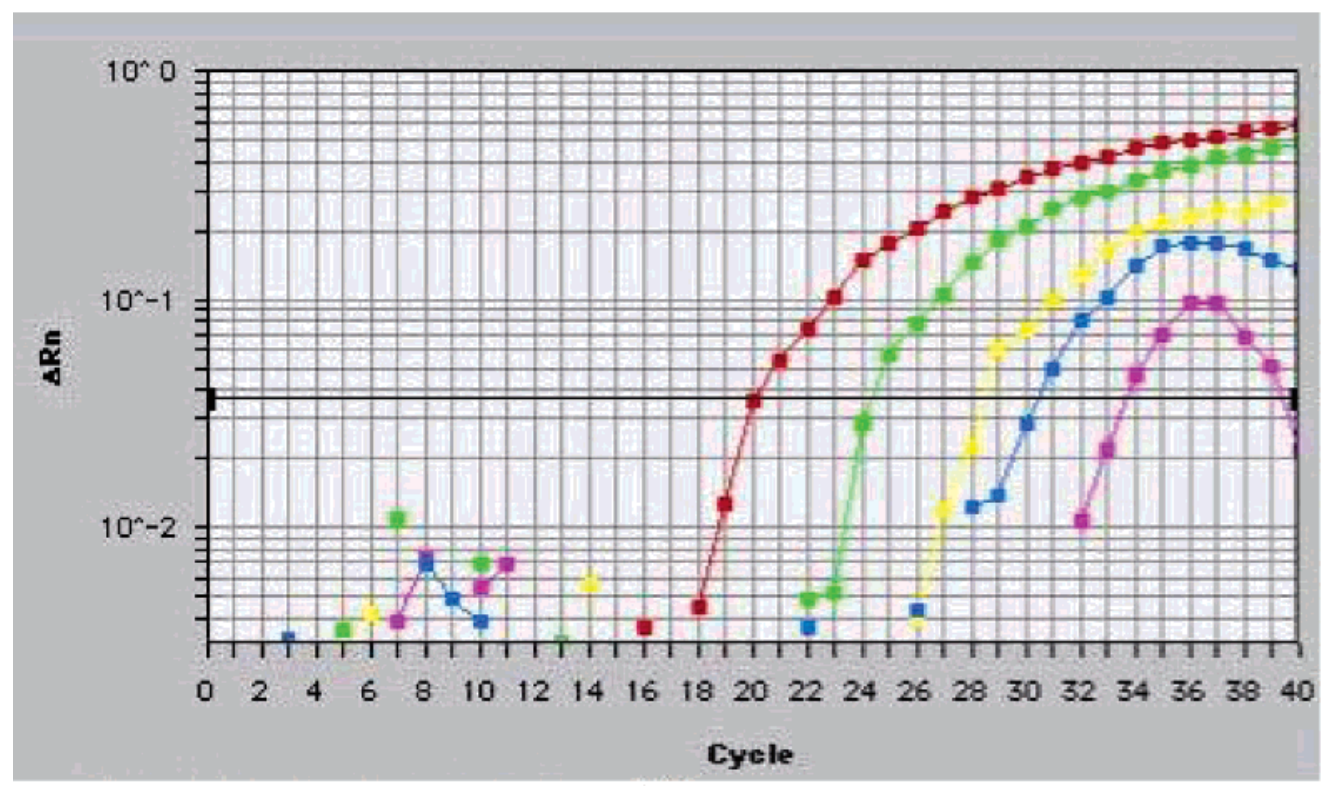

(A)

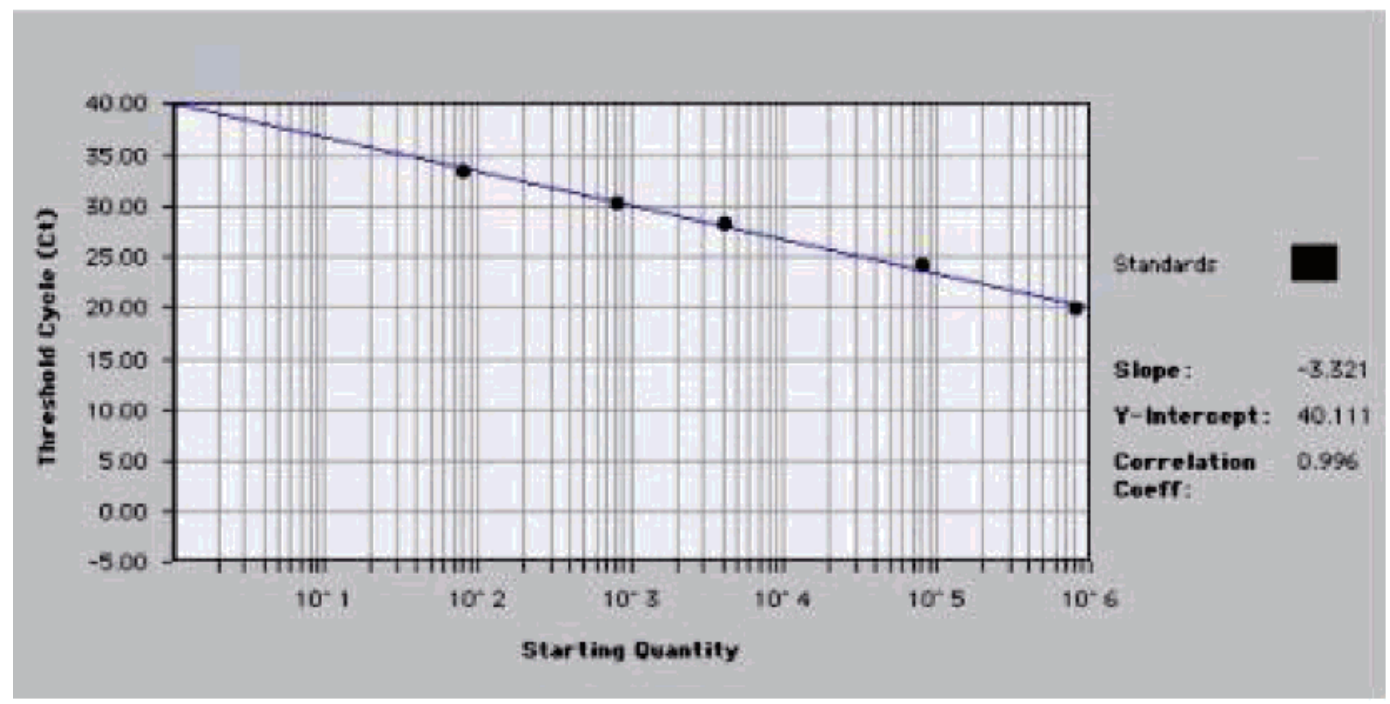

(B)

Figure 3. (A) Amplification and regression curves for the soybean endogenous le1 gene established using 800000 (red squares), 80000 (green squares), 4000 (yellow squares), 800 (blue squares), and 80 (pink squares) copies of pRRS-LUX as reference molecules. (B) Representative standard curve generated from the amplification data given in $(\mathbf{A})$.

integration locus between the recipient genome and the inserted DNA. With the event-specific methods, a positive signal will appear only in the GM-derived material, and it would be possible to identify the GM source of the DNA. The line-specific locus of transgenic integrated sequence has been revealed by Windels et al. in 2001 (9). In this study, primers RRS190FL and RRS238RU were used to amplify the event-specific region between the inserted sequence P-35S (CaMV 35S promotor) and the soybean genome.

Qualitative Analysis of RRS. Specificity and Sensitivity. Double-distilled water (nontemplate control, NTC), $5 \mathrm{ng}$ of RRS genomic DNA, and $100 \mathrm{ng}$ of RRS genomic DNA were separately amplified by Lec1618RL/Lec1439FU and RRS190FL/ RRS238RU. The results of $T_{\mathrm{m}}$ curve and electrophoretic analyses are shown in Figure 2.

The melting point of PCR products amplified by Lec1618RL/ Lec1439FU, NTC, and 5 or 100 ng of RRS genomic DNA were about 77.8 and $84.3{ }^{\circ} \mathrm{C}$ (Figure 2A). When fewer templates were involved, $5 \mathrm{ng}$ of RRS genomic DNA, PCR products had both melting peaks. According to the pattern of eletrophoretic analysis in Figure $2 \mathrm{C}$, the peak of the melting point at $77.8^{\circ} \mathrm{C}$ resulted from nonspecific PCR products (primer-dimer) shorter than $100 \mathrm{bp}$; the peak of the melting point at $84.3{ }^{\circ} \mathrm{C}$ resulted from specific PCR products. On the other hand, the specific and nonspecific PCR products, amplified by RRS190FL/ RRS238RU, were all shorter than $100 \mathrm{bp}$ and undistinguishable by electrophoresis of agarose gel (Figure 2D). According to the relationship of Lec1618RL/Lec1439FU real-time PCR results between the $T_{\mathrm{m}}$ curve and electrophoresis, the peak of the melting point at 78.3 and $73{ }^{\circ} \mathrm{C}$, amplified by RRS190FL/ RRS238RU, was identified as specific and nonspecific signal generated from specific and nonspecific PCR products.

The specificity of the LUX real-time PCR system was assessed by running real-time PCRs on $200 \mathrm{ng}$ of template DNA 


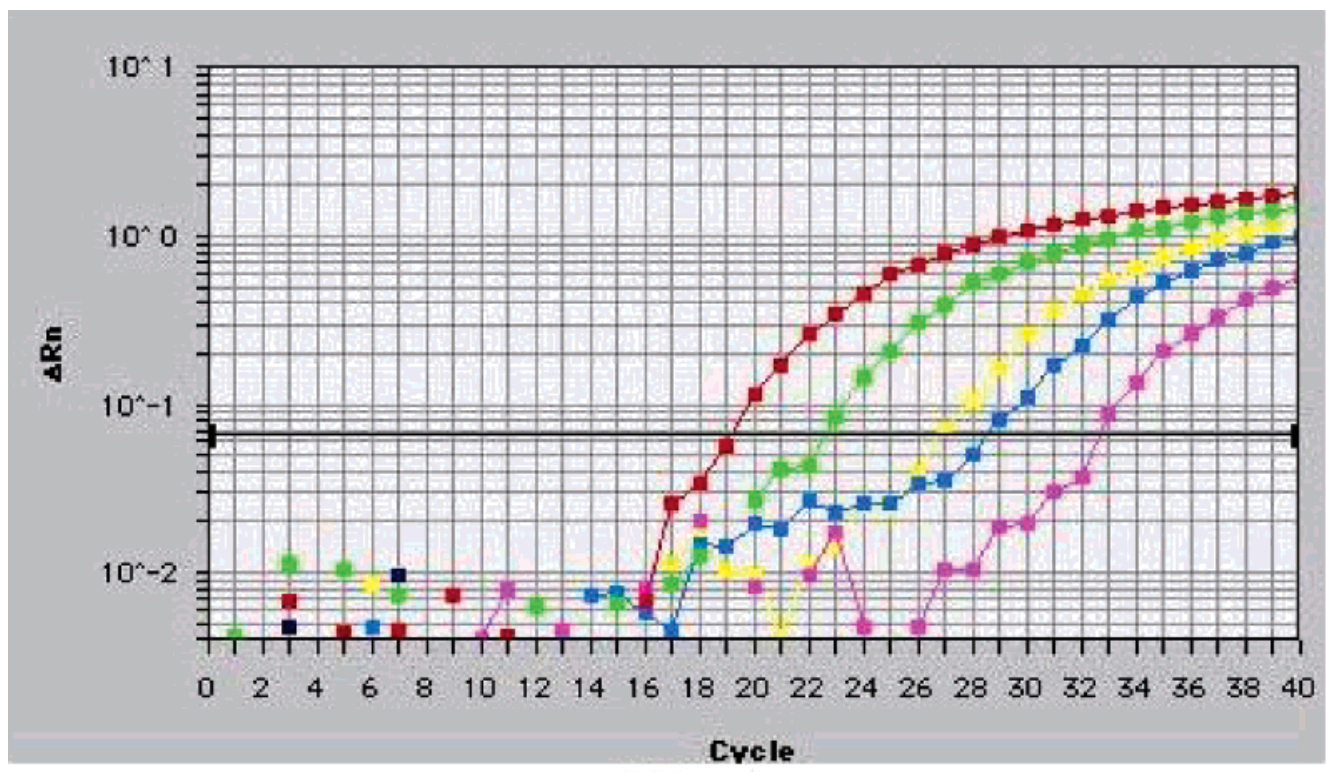

(A)

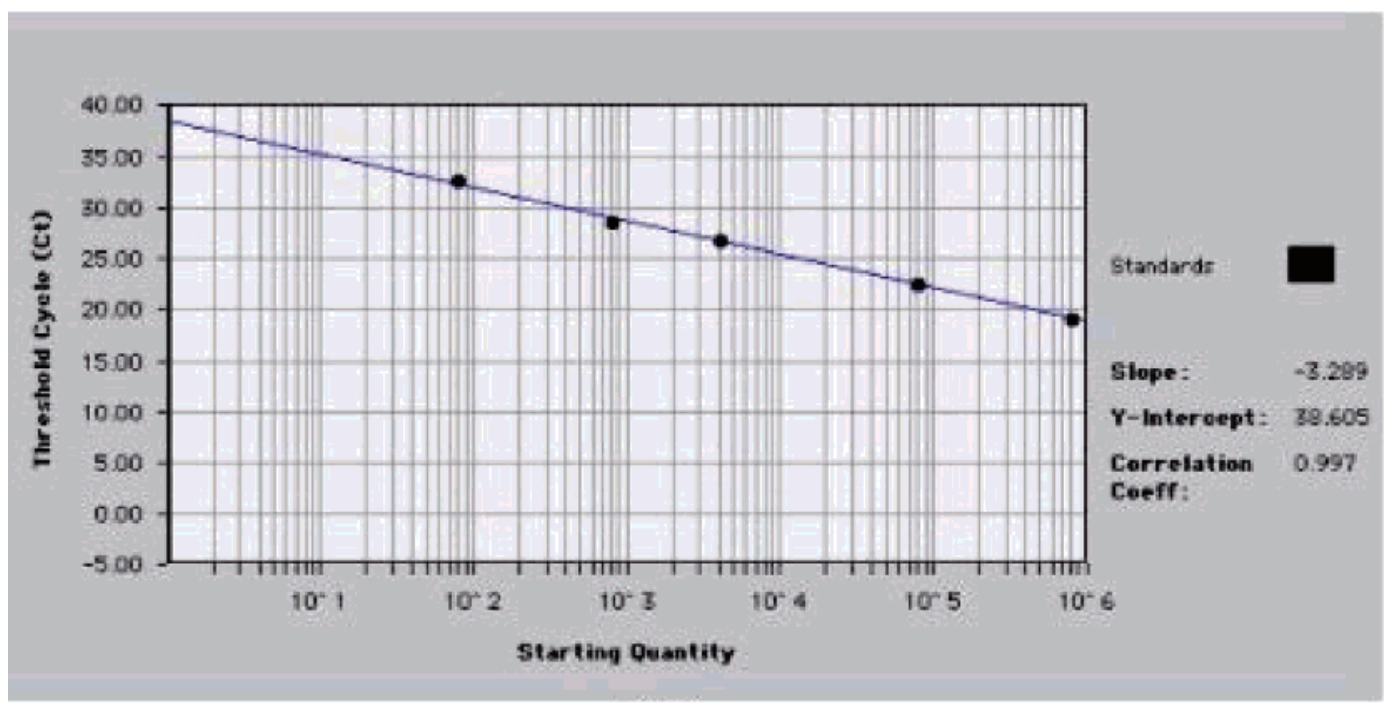

(B)

Figure 4. (A) Amplification and regression curves for the transgene of genetically modified soybean RRS established using 800000 (red squares), 80000 (green squares), 4000 (yellow squares), 800 (blue squares), and 80 (pink squares) copies of pRRS-LUX as reference molecules. (B) Representative standard curve generated from the amplification data given in $(\mathbf{A})$.

from five different GMOs and from 15 different plant species that were either evolutionarily related to soybean or frequently found in food (Table 2). Four GM maizes were selected in this study. Event176, MON810, and NK603 all carry the CaMV $35 \mathrm{~S}$ promoter. GA21 and NK603 contain the same gene, 5-enolpyruvylshikimate-3-phosphate synthase (cp4-epsps), as RRS. Many cereals, which were used in this study, prevalently used in soy-derived products, for examples, peanuts, barley; japonica rice are used in the production of sweet simmered miso, barley miso, and rice miso, respectively; wheat flour is used in the production of chili bean sauce. Therefore, a highly specific detection method would avoid the false-positive results of RRS detection in complex food. In these assays, detectable amplification was observed only with the RRS event. Besides, by using of Lec1618RL/Lec1439FU to perform real-time PCR, specific signals $\left(T_{\mathrm{m}}=84.3^{\circ} \mathrm{C}\right)$ will appear in only soybeans (Glycine $\max )$.
To test the sensitivity of the assay system, we ran real-time PCR on serial dilution of $100 \%$ RRS genomic DNA, 50, 12.5, $2.5,0.5,0.05$, and $0.0025 \mathrm{ng}$. Then, the results were identified by $T_{\mathrm{m}}$ curve analysis. As a result, the detection limit of RRSspecific detection was $\sim 0.05 \mathrm{ng}$ (Table 3). According to published data (12), one haploid genome is equivalent to 2.26 pg of genomic DNA. Therefore, $0.05 \mathrm{ng}$ of RRS genomic DNA contained $\sim 20.5$ copies of inserted DNA. This sensitivity is similar to the results of real-time PCR assays $(13,14)$.

Quantitative Analysis of RRS. Development of Real-Time Quantitative Detection system. Reference Molecule. At present, two classes of test materials are generally applied in RRS detection. One is called certified reference materials (CRMs), composed of different content GM and non-GM seed powders, produced and merchandised by the European Commission's Joint Research Centre (JRC), the Institute for Reference Materials and Measurements (IRMM), in Geel, Belgium (15- 
Table 4. Accuracy Statistics for Quantitative Method

\begin{tabular}{|c|c|c|c|c|c|c|c|c|}
\hline \multirow[b]{3}{*}{$\begin{array}{l}\text { GM } \\
\text { line }\end{array}$} & \multirow[b]{3}{*}{$\begin{array}{l}\text { true } \\
\text { value (\%) }\end{array}$} & \multirow[b]{3}{*}{$\begin{array}{l}\text { coefficient } \\
\text { value }\left(C_{V}\right)\end{array}$} & \multicolumn{6}{|c|}{ accuracy } \\
\hline & & & \multicolumn{3}{|c|}{ trueness } & \multicolumn{3}{|c|}{ precision } \\
\hline & & & $\begin{array}{c}\text { mean } \\
(\%)\end{array}$ & $\begin{array}{l}\text { biassa }^{a} \\
(\%)\end{array}$ & $\mathrm{C} \mid 95 \%{ }^{b}$ & $S^{c}$ & $\begin{array}{l}C_{V}^{d} \\
(\%)\end{array}$ & $n^{c}$ \\
\hline RRS & $\begin{array}{l}5 \\
2 \\
1 \\
0.5 \\
0.1\end{array}$ & 1.8 & $\begin{array}{l}5.29 \\
1.92 \\
0.89 \\
0.42 \\
0.11\end{array}$ & $\begin{array}{r}5.80 \\
-4.00 \\
-11.00 \\
-16.40 \\
8.00\end{array}$ & $\begin{array}{l}0.24 \\
0.72 \\
0.33 \\
0.06 \\
0.03\end{array}$ & $\begin{array}{l}0.22 \\
0.64 \\
0.29 \\
0.06 \\
0.03\end{array}$ & $\begin{array}{r}4.16 \\
33.33 \\
32.58 \\
14.29 \\
27.27\end{array}$ & $\begin{array}{l}3 \\
3 \\
3 \\
3 \\
3\end{array}$ \\
\hline
\end{tabular}

${ }^{a}$ Bias $=$ (mean value - true value) $/$ true value $\times 100 .{ }^{b} \mathrm{Cl} 95 \%=$ relative $95 \%$ confidence interval. ${ }^{c} \mathrm{SD}$, standard deviation. ${ }^{d} \mathrm{C}_{\mathrm{V}}$, coefficient values are calculated by dividing standard deviation by mean value and are given in percent. ${ }^{e}$ Experiments were performed at least three times.

22). The other class of test materials is double-stranded DNA plasmids carrying a PCR target sequence or PCR hybrid amplicons $(11,23-25)$. For GMO, analytical methods are usually validated with CRMs. However, CRMs are presently only available for a limited number of GMOs, and their suitability for validation of real-time quantitative PCR methods may be questioned (26). Therefore, the second class of test materials was taken as reference molecules in this study. The method of Kuribara mentioned in 2002 was followed to construct a plasmid, as shown as Figure 1, containing both of the target sequences of the real-time PCR as a reference molecule (11).

Because plasmid DNAs are easily amplifiable and the process of DNA extraction is simple, plasmid DNAs are more economical and convenient reference molecules than CRMs.

Construction of Standard Curves. According to the plasmid pRRS-LUX size (3422 bp), 1 molecule corresponds to $3.42 \mathrm{ag}$ of plasmid DNA (27). The purified plasmid DNA was serially diluted in doubled-distilled water to yield 80, 800, 4000, 80 000, and 800000 molecules of plasmid per $5 \mu \mathrm{L}$. On the basis of the genome size of soybean (12), we considered that the range of copy numbers from 80 to 800000 was sufficient to quantitate GMO from 0.1 to $100 \%$ in $200 \mathrm{ng}$ of the template for one reaction. Accordingly, five levels of concentration of reference molecules were set to 80, 800, 4000, 80 000, and 800000 copies per reaction for the calibration. The ranges of quantitation meet the labeling requirement of regulations in the EU (0.9\%), Taiwan $(5 \%)$, and Japan $(5 \%)$.

The linearities of standard curves were confirmed by quantitative PCRs by using the reference molecules and the designed PCR systems. Despite the wide linear range of plasmid target molecules to build the standard curves (80-800 000 copies), high reproducibility and accuracy can be obtained, as shown in Figures 3 and 4. In theory, because both strands of the DNA template are copied during PCR, there is an exponential increase of the number of copies of the gene.

We can calculate the PCR efficiency of the real-time PCR according to (19)

$$
\text { PCR efficiency }(\%)=\left(10^{(\mid \text {slope } \mid-1)}-1\right) \times 100
$$

According to the equation, if the efficiency of real-time PCR is $100 \%$, the slope of the standard curve is $-3.32(20)$. Therefore, a very efficient amplification was obtained as indicated by the slope of the linear regression analysis $(-3.321$ and -3.299$)$. In addition, the square regression correlations $\left(R^{2}\right)$ were 0.996 and 0.997 for the le 1 gene and RRS amplicons, respectively. Good linearity between copy number and fluorescence values $\left(C_{\mathrm{t}}\right)$ visualized in the calibration curves in Figures $\mathbf{3}$ and $\mathbf{4}$, that is, high agreement between the amount of template (ln input DNA) and amount of product ( $C_{\mathrm{t}}$ values), indicates that this assay is well suited for quantitative measurements.

Coefficient Value $\left(C_{V}\right)$. The ratios of r-DNA sequence to endogenous sequence in GM seed, calculated according to eq 2 , are defined as coefficient value $\left(C_{\mathrm{V}}\right)$. In addition, the GMO amounts (percent) are calculated by according to eq 3 and the defined $C_{\mathrm{V}}$ values (11).

$$
C_{\mathrm{V}}=\frac{\begin{array}{c}
\text { copies of } \mathrm{r}-\mathrm{DNA} \text { sequence in the } \\
\text { DNA extracted from GM seeds }
\end{array}}{\text { copies of endogenous sequence in }}
$$

$$
\begin{aligned}
& \text { copies of r-DNA sequence in the } \\
& \text { GMO amount }(\%)=\frac{\text { DNA extracted from GM seeds } \times 100}{\text { copies of endogenous sequence in the }} \\
& \text { DNA extracted from GM seeds } \times C_{\mathrm{V}}
\end{aligned}
$$

According to the previous study (28), the ratio of the $C_{\mathrm{V}}$ values of GM seeds corresponded to the copy number of the gene introduced into RRS (29). The copy numbers of both the junction sequence and the endogenous gene lel were 1 , so the ideal $C_{\mathrm{V}}$ values should be 1 . However, the $C_{\mathrm{V}}$ value of the RRSspecific sequence was 1.8 in this study. Similar results were also observed in the previous study (19) of GM maize, MON810 and NK603. The difference between experimental and theoreti-

\begin{tabular}{|c|c|c|c|c|c|c|}
\hline ref & GM lines & $\begin{array}{l}\text { real-time PCR } \\
\text { system }\end{array}$ & RM & range (\%) & $C_{V}(\%)$ & bias (\%) \\
\hline Vaïtilingom et al. (15) & Bt 176, RRS & TaqMan & seeds & $0.1-2.0$ & $5-20$ & \\
\hline BgVV, EU Tender report (16) & RRS, Bt 176 & TaqMan & seeds & $0.1-100$ & $\sim 25$ & \\
\hline Berdal and Holst-Jensen (18) & RRS & TaqMan & seeds & $0.1-100$ & $15-33$ & -10 to 28 \\
\hline Höhne et al. (2002) & $\begin{array}{l}\text { CaMv 35S promoter (Bt11, Bt176, } \\
\text { MON810, T25) }\end{array}$ & TaqMan & seeds & $0.1-1.0$ & $19-40$ & -3 to 41 \\
\hline Alary et al. (2002) & CaMv 35S promoter (RRS, Bt176) & TaqMan & seeds & $0.1-10$ & $4-17$ & -50 to 56 \\
\hline Permingeat et al. (21) & MON810, RRS & TaqMan & seeds & $0.1-0.5$ & $4-17$ & -9 to 20 \\
\hline $\begin{array}{l}\text { Brodmann et al. (2002) } \\
\text { Kuribara et al. (11) }\end{array}$ & MON810, Bt176, Bt11, T25, GA21 & TaqMan & seeds & $0.1-100$ & $\begin{array}{l}5-20 \\
<6\end{array}$ & $\begin{array}{l}-10 \text { to } 13 \\
-3.2 \text { to } 46\end{array}$ \\
\hline $\begin{array}{l}\text { Shindo et al. (28) (13 laboratories } \\
\text { from Japan, Korea, U.S.A.) }\end{array}$ & $\begin{array}{l}\text { MON810, Event176, Bt11, T25, } \\
\text { GA21, and RRS }\end{array}$ & TaqMan & plasmids & $0.1-100$ & $6-32$ & -9.0 to 39 \\
\hline Pardigol et al. (24) & CaMV 35S promoter (MON810), RRS & TaqMan & hybrid amplicons & $0.1-100$ & $2-33$ & 0.4 to 30 \\
\hline Huang and Pan (19) & MON810, NK603, GA21 & TaqMan & plasmids & $0.1-100$ & $0.3-17$ & -11 to 22 \\
\hline Rho et al. (25) & $\begin{array}{l}\text { NewLeaf (Superior), NewLeaf (Russet } \\
\text { Burbank), NewLeaf Plus, } \\
\text { NewLeaf } Y\end{array}$ & TaqMan & plasmid & $0.5-5.0$ & $4-27$ & -26 to 33 \\
\hline this study & RRS & LUX & plasmid & $0.1-100$ & $4-33$ & -16 to 8 \\
\hline
\end{tabular}
cal values was suspected to be generated by differences of PCR efficiencies $(11,19)$.

Table 5. Comparison the GM Lines, Real-Time PCR Systems, Reference Materials, Ranges of Quantitation, Coefficient of Variation, and Bias (True Value) in Previous Studies 
Accuracy of Quantitation. The calculated mean, bias, and relative standard deviation (RSD) at each mixing level are shown in Table 4. Repeated measurement of standard DNA solution leads to RSDs for all methods in the range of 4.16-33.33\%. In addition, the bias (mean-true value, \%) ranged from -16 to $8 \%$. RSDs and bias in similar ranges have been published earlier in connection with other quantitative GMO detection systems as shown in Table 5. Besides, low concentration of the target DNA leads to higher variation among parallel runs than does high concentration (13). Therefore, previous studies mentioned low precision and trueness observed in low levels of DNA content compared with higher ones $(13,28)$.

In conclusion, we report a different strategy, that is, LUX, for the reliable and accurate detection, identification, and quantification of the transgenic soybean line Roundup Ready. Its specificity relies on the amplification of a region unique to RRS. The assay proved to have allowable levels of accuracy and precision.

\section{LITERATURE CITED}

(1) James, C. Global status of commercialized transgenic crops: 2003. ISAAA Briefs 2003, 30.

(2) Pan, T. M. The impact and advantage of genetically modified crop. Bioindustry 2002, 13, 441-451.

(3) Anklam, E.; Gadani, F.; Heinze, P.; Pijnenburg, H.; Eede, G. V. D. Analytical methods for detection and determination of genetically modified organisms in agricultural crops and plantderived food products. Eur. Food Res. Technol. 2002, 214, 3-26.

(4) Jung, R.; Soondrum, K.; Neumaier, M. Quantitative PCR. Clin. Chem. Lab. Med. 2000, 38, 833-836.

(5) Nazarenko, I.; Pires, R.; Lowe, B.; Obaidy, M.; Rashtchian, A. Effect of primary and secondary structure of oligodeoxyribonucleotides on the fluorescent properties of conjugated dyes. Nucleic Acids Res. 2002, 30, 2089-2195.

(6) Mackay, I. M.; Arden, K. E.; Nitsche, A. Real-time PCR in virology. Nucleic Acids Res. 2002, 30, 1295-1305.

(7) Nazarenko, I.; Lowe, B.; Darfler, M.; Ikonomi, P.; Schuster, D.; Rashtchian, A. Multiplex quantitative PCR using self-quenched primers labeled with a single fluorophore. Nucleic Acids Res. 2002, 30, e37.

(8) Lowe, B.; Avila, H. A.; Bloom, F. B.; Gleeson, M.; Kusser, W. Quantitation of gene expression in neural precursors by reversetranscription polymerase chain reaction using self-quenched, fluorogenic primers. Anal. Biochem. 2003, 315, 95-105.

(9) Windels, P.; Taverniers, I.; Depicker, A.; Van Bockstaele, E.; De Loose, M. Characterisation of the Roundup Ready soybean insert. Eur. Food Res. Technol. 2001, 213, 107-112.

(10) Lipp, M.; Brodmann, P.; Pietsch, K.; Pauwels, J.; Anklam, E. IUPAC collaborative trial study of a method to detect genetically modified soybeans and maize in dried powder. J. AOAC Int. 1999, 82, 923-928.

(11) Kuribara, H.; Shindo, Y.; Matsuoka, T.; Takubo, K.; Futo, S.; Aoki, N.; Hirao, T.; Akiyama, H.; Goda, Y.; Toyoda, M.; Hino, A. Novel reference molecules for quantitation of genetically modified maize and soybean. J. AOAC Int. 2002, 85, 10771189.

(12) Plant DNA C-values Database, 2004; http://www.rbgkew.org.uk/ $\mathrm{cval} /$ database1.html.

(13) Rønning, S. B.; Vatilingom, M.; Berdal, K. G.; Holst-Jensen, A. Event specific real-time quantitative PCR for genetically modified Bt11 maize (Zea mays). Eur. Food Res. Technol. 2003, 216, 347-354.

(14) Hernández, M.; Esteve, T.; Prat, S.; Pla, M. Development of real-time PCR systems based on SYBR Green I, Amplifluor and
TaqMan technologies for specific quantitative detection of the transgenic maize event GA21. J. Cereal Sci. 2004, 39, 99107.

(15) Vaitilingom, M.; Pijnenburg, H.; Gendre, F.; Brignon, P. Realtime quantitative PCR detection of genetically modified Maximizer maize and Roundup Ready soybean in some representative foods. J. Agric. Food Chem. 1999, 47, 5261-5266.

(16) Institute for Health Protection of Consumers and Veterinary Medicine $(\mathrm{BgVV})$. Development of qualitative as well as quantitative detection methods to identify a genetic modification in soybean and maize products. Report of the EU tender $\mathrm{N}$. XXIV/9898A3/001, 2000.

(17) Terry, C. F.; Harris, N. Event-specific detection of Roundup Ready Soya using two different real time PCR detection chemistries. Eur. Food Res. Technol. 2001, 213, 425-431.

(18) Berdal, K. G.; Holst-Jensen, A. Roundup Ready soybean eventspecific real-time quantitative PCR assay and estimation of the practical detection and quantification limits in GMO analyses. Eur. Food Res. Technol. 2001, 213, 432-438.

(19) Huang, H. Y.; Pan, T. M. Detection of genetically modified maize MON810 and NK603 by multiplex and real-Time polymerase chain reaction methods. J. Agric. Food Chem. 2004, 52, 32643268.

(20) Terry, C. F.; Shanahan, D. J.; Ballam, L. D.; Harris, N.; McDowell, D. G.; Parkes, H. C. Real-time detection of genetically modified soya using LightCycler and ABI 7700 platforms with TaqMan, Scorpion and SYBR Green I chemistries. $J$. AOAC. Int. 2002, 85, 938-944.

(21) Permingeat, H. R.; Reggiardo, M. I.; Vallejos, R. H. Detection and quantification of transgenes in grains by multiplex and realtime PCR. J. Agric. Food Chem. 2002, 50, 4431-4436.

(22) Hernández, M.; Rodríguez-Lázaro, D.; Esteve, T.; Prat, S.; Pla, M. Development of melting temperature-based SYBR Green I Polymerase Chain Reaction methods for multiplex genetically modified organism detection. Anal. Biochem. 2003, 323, 164170.

(23) Taverniers, I.; Windels, P.; Bockstaele, E. V.; Loose, M. D. Use of cloned DNA fragments for event-specific quantification of genetically modified organisms in pure and mixed food products. Eur. Food Res. Technol. 2001, 213, 417-424.

(24) Pardigol, A.; Guillet, S.; Pöpping, B. A simple procedure for quantification of genetically modified organisms using hybrid amplicon standards. Eur. Food Res. Technol. 2003, 216, 412420.

(25) Rho, J. K.; Lee, T.; Jung, S. I.; Kim, T. S.; Park, Y. H.; Kim, Y. M. Qualitative and quantitative PCR methods for detection of three lines of genetically modified potaoes. J. Agric. Food Chem. 2004, 52, 3269-3274.

(26) Holst-Jensen, A.; Rønning, S. B.; Løvseth, A.; Berdal, K. G. PCR technology for screening and quantification of genetically modified organisms (GMOs). Anal. Bioanal. Chem. 2003, 375, 985-993.

(27) Eede, G. V. D.; Kay, S.; Anklam, E. Analytical challenges: bridging gap from regulation to enforcement. J. AOAC Int. 2002, $85,757-761$

(28) Shindo, Y.; Kuribara, H.; Matsuoka, T.; Futo, S.; Sawada, C.; Shono, J.; Akiyama, H.; Goda, Y.; Toyoda, M.; Hino, A. Validation of real-time PCR analyses for line-specific quantitation of genetically modified maize and soybean using new reference molecules. J. AOAC Int. 2002, 85, 1119-1126.

(29) Monsanto. 2004; http://www.monsanto.com/monsanto/content/our_pledge/transparency/prod_safety/roundup_soybean/pss.pdf.

Received for review August 27, 2004. Revised manuscript received March 2, 2005. Accepted March 15, 2005.

JF048580X 